\title{
O SELO DA HONESTIDADE: A VIRGINDADE E O CONTROLE MORAL DO CORPO
}

THE HONESTY SEAL: VIRGINITY AND THE MORAL CONTROL OF THE BODY

\author{
Claudia Schemes* \\ claudias@feevale.b \\ Magna Lima Magalhães** \\ magna@feevale.br
}

RESUMO: Este artigo analisa a questão do controle do corpo feminino e a importância e valorização da virgindade para as mulheres na cidade de Novo Hamburgo (RS) nos anos 1930 que, para serem consideradas honradas, deveriam manter sua virgindade até o casamento e, portanto, distanciar-se dos apelos da sexualidade. Nossas reflexões serão realizadas através da utilização dos processoscrime que envolvem o defloramento na cidade citada e que nos permitem observar quais eram as condutas morais e as representações construídas sobre a mulher deflorada.

PALAVRAS-CHAVE: corpo, defloramento, mulher.

ABSTRACT: This article analyzes the control of the female body and the importance and value of virginity for women in the town of Novo Hamburgo (RS) in 1930's in order to be considered honorable, should keep her virginity until marriage, and therefore distance to the appeals of sexuality. Our discussions will be conducted through the use of criminal proceedings involving the crime of deflowering in the city and cited that allow us to observe what were the moral conduct and representations built on the woman deflowered.

KEYWORDS: body, defloration, woman.

\section{Introdução}

Este texto versa sobre a importância e a valorização da virgindade como um quesito para as mulheres serem consideradas honradas. O controle do corpo feminino, a conservação do mesmo intacto, sem a mácula da vergonha, ou seja, da perda da virgindade antes das núpcias impunha à mulher uma exigência de conduta social que estabelecia o

\footnotetext{
* Doutorado pela Pontifícia Universidade Católica do RS - PUC (2006). Professora dos cursos de graduação de História e Moda e Mestrado em Processos e Manifestações Culturais da Universidade Feevale (Novo Hamburgo/RS).

${ }^{* *}$ Doutorado pela Universidade do Vale do Rio dos Sinos (2010). Atualmente é professora da Universidade Feevale.
} 
controle feminino sobre seu corpo e a obrigatoriedade de distanciar-se dos apelos da sexualidade. Nossas reflexões se respaldam nos processos-crime ocorridos na cidade de Novo Hamburgo (RS) nos anos 1930 e que trazem à tona o defloramento como um crime.

Objetivamos, a partir da fonte histórica elencada, trazer à tona as diretrizes morais que conduziam e cercavam as mulheres, especialmente as jovens, bem como as "marcas" sociais as quais elas estavam sujeitas a partir do defloramento. Discutimos neste estudo a constituição de uma representação sobre as mulheres que envolvia uma avaliação de conduta moral e comportamental que delimitava os espaços e os papéis da mulher em meio à sociedade.

Conforme Pinsky (2012, p.471)

No Brasil, [...] mesmo com a entrada do século XX, permaneceram as heranças européias do medievo que valorizavam a natureza sexual das mulheres e condenavam as que se deleitavam no sexo. O hímen continuava a ser o capital precioso das jovens casadoiras e a honra sexual feminina ainda era assunto de família, já que comprometia diretamente os parentes próximos. As mulheres deveriam ser vigiadas e seu sexo protegido dos sedutores, dos estupradores [...].

Tal perspectiva possibilita entender que "há sempre disputa acerca dos valores e sentidos sobre o corpo e seu uso, em que estão em jogo classificações sociais, posições de prestígio e a produção de acusações." (MORAES, 2011, p.439). Sendo assim, o corpo é regulado, fiscalizado, normatizado e deve ser entendido a partir da sua relação com a sociedade, ou seja, inserido na complexidade dos processos históricos.

Neste sentido, relacionar virgindade e sua valorização em determinado tempo possibilita a elaboração de reflexões sobre as condutas e papéis sociais direcionados à mulher. O estudo está inserido no projeto de pesquisa intitulado Arrabaldes teutobrasileiros: espacialidade, moral e controle em Novo Hamburgo na primeira metade do século XX, vinculado ao grupo de pesquisa Cultura e Memória da Comunidade que tem empreendido um esforço de repensar, através de diferentes pesquisas, a construção histórica da região do Vale do Sinos e sua diversidade.

Entendemos que a condição feminina é constituída histórica e socialmente e que as mulheres como agentes históricos subvertem ordens e reivindicam espaços.

\section{A mulher no Brasil nos anos 1930}


A partir dos anos 1930 a mulher brasileira conquista direitos até então inexistentes, como o direito ao voto, por exemplo. No ano de 1939 Getúlio Vargas, presidente da época, propôs um "estatuto de família" que, dentre outras questões, previa a progressiva restrição da admissão de mulheres nos empregos públicos e privados. Dizia o estatuto que "não poderão as mulheres ser admitidas senão aos empregos próprios da natureza feminina, e dentro dos estritos limites da convivência familiar." Para parte da Igreja Católica, a mulher que trabalhava fora "funcionária ou operária, ou não é mãe, ou não é boa mãe, ou não é boa funcionária” (Pe. Leonel França, apud Schwartzman, 1984:113).

Para Schwartzman (1984), estas restrições impostas ao trabalho feminino estavam relacionadas à ideia vigente da completa divisão de papéis e de responsabilidade dentro do casamento. Um dos artigos do estatuto dizia que: “Às mulheres será dada uma educação que as torne afeiçoadas ao casamento, desejosas da maternidade, competentes para a criação dos filhos e capazes da administração da casa." Tal perspectiva nos reporta a instauração de uma ordem burguesa, vinculada a modernização e a higienização da sociedade que, conforme Soihet (1997: 362), foi construída durante a Bélle Époque (1890-1920), assim, uma medicina social é constituída e no tocante as mulheres exigia uma postura de submissão, "um comportamento que não maculasse a honra", restringindo o exercício da sexualidade para as mulheres e a obrigatoriedade do casamento.

Outro exemplo das restrições públicas impostas às mulheres foram as publicadas na Revista Feminina, magazine que circulou no Brasil entre 1915 e 1925, considerado um dos instrumentos mais fortes de perpetuação do comportamento conservador que a sociedade impunha ao sexo feminino. Para Maluf \& Mott (1998: 373), "o dever ser das mulheres brasileiras nas três primeiras décadas do século foi [...] traçado por um preciso e vigoroso discurso ideológico, que reunia conservadores e diferentes matizes de reformistas e que acabou por desumanizá-las como sujeitos históricos."

No final da década de trinta, as discussões a respeito do papel da mulher na sociedade diminuíram, e as relações de gênero tinham mudado o suficiente para acomodar as realidades da sociedade urbano industrial que se impunha, "mas não o suficiente para balançar as bases patriarcais da cultura brasileira, pois o viés da educação das mulheres assegurava que elas continuassem subordinadas aos homens" (BESSE, apud BRUSCHINI, 1990: 6).

Essas transformações pelas quais a mulher passou desde as primeiras décadas do século XX no Brasil geraram inúmeras discussões a respeito do seu papel, pois ela deixou a esfera do privado e buscou engajamento na esfera do público, ou seja, queria ter os seus direitos mesmo que em alguns momentos houvesse fortes sinais de restrição de atuação da mulher. 
De acordo com Reichert (2008, p.16),

Do final da Primeira Guerra Mundial até o período inaugurado pela Revolução de 30, o Brasil vivenciou uma série de contestações à ordem política e social vigente, percebida por alguns reformadores como um atraso a ser superado. Uma área em que houve contestações foi precisamente aquela referente à vida das mulheres - o espaço que podiam ocupar, o padrão de vida que podiam seguir e os direitos de que dispunham. A contestação assumiu várias formas e manifestou-se através de diversos veículos: revistas, organizações feministas.

Cabe ressaltar, conforme nos informa Chalhoub (2001), que nem todas as mulheres eram submissas e tinham sua vida restrita ao lar, pois as mulheres trabalhadoras não possuíam os rígidos padrões comportamentais dominantes de docilidade, passividade ou "mulher-vítima". Para o autor, as relações materiais de vida determinavam uma relação homem-mulher "bipolarizada", com uma maior divisão de poder entre eles.

Entretanto, o que percebemos foi que a entrada da mulher no mercado de trabalho remunerado "criou uma divisão sexual do trabalho na esfera pública que espelhava e reforçava a divisão sexual do trabalho na família." Já que esta tinha se tornado menos rígida hierarquicamente, mas "não menos importante como uma instituição para controlar a sexualidade das mulheres e preservar as relações de classe" (BESSE, apud BRUSCHINI, 1990, p. 6).

Nesse sentido, Rago (1987, p. 63) diz que o próprio movimento operário nas primeiras décadas do século XX no Brasil, que era liderado pelos homens, atuou no sentido de "fortalecer a intenção disciplinadora de deslocamento da mulher da esfera pública do trabalho e da vida social para o espaço provado do lar." O modelo de comportamento feminino determinou, inclusive, as suas opções profissionais, ou seja, elas poderiam optar entre ser professoras primárias, enfermeiras, domésticas, operárias, costureiras, telefonistas, datilógrafas. Por outro lado, não somente havia a necessidade de obediência a tais orientações, mas também aos comportamentos que as mulheres deveriam apresentar na sociedade, no que concerne aos movimentos desses corpos na sociedade.

\section{Virgindade e honra em Novo Hamburgo}

A cidade de Novo Hamburgo está situada na região do Vale do Rio dos Sinos (RS) e foi emancipada em 1927 de São Leopoldo, sendo um espaço de forte presença da cultura germânica. Contava na época de sua emancipação com um incipiente, mas importante 
desenvolvimento industrial. Uma cidade pequena que nos primeiros anos do século $\mathrm{XX}$ tinha sua economia centrada no setor coureiro-calçadista, contando com curtumes, selarias e fábricas de calçados que ali se desenvolveram. A emancipação reverteu em novos tempos para a cidade, através de um cenário que se alterava fornecendo gradativamente uma face mais urbana, modificando a estética e a espacialidade do antigo distrito. Apesar de suas alterações e sua "modernidade" a moralidade estabelecida não diferia de outros espaços nacionais e impunha às mulheres determinados comportamentos, esperando desses indivíduos certas atitudes, tanto no que diz respeito a suas escolhas profissionais, quanto aos seus relacionamentos afetivos.

Segundo Jeferson Selbach (1999, p. 59), o novo município era moralista e rigorosamente fechado, e a jovem de família tradicional era "mandada para internatos com a finalidade de se educar para o noivado e o matrimônio [...] e para dirigir o futuro lar e a lida doméstica de costurar, remendar, lavar e engomar, higienizar a casa e lidar com maestria na arte da culinária."

Sílvia Petersen (1986), quando trabalha com construção da imagem feminina no Rio Grande do Sul, lembra que o ideário positivista, fortemente marcado no Estado, confere à mulher a superioridade espiritual em relação aos homens, ou seja, atribui-lhe como funções fundamentais a maternidade, a guarda do lar e a instrução dos filhos, garantindo, assim, não apenas a manutenção da espécie, mas também o desenvolvimento moral da humanidade através da educação.

Nossas reflexões estão restritas as mulheres da região do Vale do Rio dos Sinos e mais especificamente sobre as moradoras de Novo Hamburgo e as matizes morais/comportamentais que circundavam a defesa da virgindade e da honra. Temos por objetivo fazer um exercício de (re)pensar a construção histórica da região e suas relações de poder, especialmente de gênero a partir do crime sexual de defloramento.

Os estudos historiográficos sobre a mulher e as discussões sobre gênero e seus avanços possibilitam visualizar a ação feminina no macro espaço histórico, mas também na esfera micro do cotidiano, destacando, neste último, as mulheres e suas práticas cotidianas e as brechas das quais elas lançavam mão para lidar com as relações de poder estipuladas em uma sociedade. Os processos crimes de defloramento servem de esteio para nossas reflexões tendo como referências trabalhos como o de Caulfield (2000), Esteves (1989) e Chalhoub (2001), os quais utilizam os processos criminais como fonte histórica.

É relevante destacar que a discussão das relações de gênero, os diferentes papéis assumidos pelas mulheres, as condutas morais e sociais que as atingiam e suas ações frente 
as mesmas na história local é algo ainda por explorar. ${ }^{1}$ No recorte temporal estabelecido para o estudo (anos 1930), Novo Hamburgo a "passos rápidos" galgava o título que mais tarde receberia de "Manchester Brasileira", uma cidade que prosperava a partir da industrialização e que tinha no "tripé" trabalho, ordem e progresso elementos constituintes da sua identidade.

Portanto, é a partir deste cenário local, mas não excluído das premissas emolduradas em âmbito nacional, que pretendemos elaborar algumas reflexões sobre o controle do corpo, o valor da virgindade e a "defesa da honra" a partir do poder jurídico que servia como mecanismo normatizador da sociedade. Para tanto, pretendemos com os processos-crime apresentados, conjecturar a respeito de exigências comportamentais que eram exigidas das mulheres, bem como refletir sobre o posicionamento masculino verificado nos autos do processo.

\section{Entregava-se a qualquer homem...}

Em junho de 1934 as palavras pronunciadas por José Nunes ao juiz açoitaram a moral e a honra de Melita dos Santos. O réu não poupava esforços ao tentar provar a sua inocência e apontar a vítima como responsável pela cópula carnal. Nunes acusava a jovem de 18 anos de idade, filha da viúva Hilda dos Santos, ambas moradoras da periferia da cidade de Novo Hamburgo de "uma mulher reconhecidamente vagabunda, dessas mulheres criadas à vontade e por isso, há muito tempo, entregava-se a qualquer homem." De acordo com José Nunes, acusado pelo defloramento² de Melita a "suposta vítima, já há três anos, dormia com rapazes e que, até nas estradas públicas, durante a noite mantinha, com eles, relações sexuais, para o que era conduzida de automóvel a lugares ermos."3

\footnotetext{
${ }^{1}$ Segundo Joan Scott, o termo gênero parece ter sido utilizado, inicialmente, pelas feministas americanas que rejeitavam o determinismo biológico presente nos termos sexo ou diferença sexual. A autora salienta que gênero pode se referir ao aspecto relacional das definições normativas de feminilidade. Além disso, Scott menciona que o termo pode ser substituído por mulher (dando caráter erudito ao estudo), ou como designador de relações sociais entre os sexos. Scott sugere que as relações de gênero estão imbricadas com as de poder, pois fundamenta os espaços ocupados por esses indivíduos - homens e mulheres.

${ }^{2}$ Entende-se por defloramento "atitude na qual a mulher de menor idade é deflorada mediante sedução e engano, o código penal não só trata de proteger a honra individual da mulher, mas principalmente, visa garantir ao marido e/ou à família a estabilidade necessária para a manutenção das instituições sociais celulares: casamento e família" (FAUSTO, 2004, p. 194-196).

Em janeiro de 1942, entrou em vigor o Código Penal aprovado em 1940 que alterou a tipicidade do crime de defloramento. O novo código reduzia a idade máxima de 21 anos para 18 anos e passava a chamar o crime não mais de defloramento, mas crime de sedução.

${ }^{3}$ Arquivo Público de Estado do Rio Grande do Sul, processo criminal, ano 1934.
} 
O acusado, com suas palavras, atacava não só Melita, mas também Hilda, posto que a responsabilidade da educação e da boa conduta da moça séria recaía especialmente sobre os ombros femininos, portanto da mãe. Ao mencionar "criadas a vontade" ampliava sua defesa usando como estratagema um discurso moralizante envolvendo o papel da mulher na sociedade, ou seja, de filha, esposa e mãe que deveria ser zelosa e responsável, recatada, submissa e norteadora da moral e dos bons costumes. Definições típicas para a mulher do início do século XX.

Apesar de mais de uma testemunha atestar a boa conduta da moça como sendo de família, séria e trabalhadora, para Nunes o defloramento ocorrera devido aos seus desregramentos sociais e, por mais de uma vez, afirmava que nunca havia prometido casamento.

De acordo com Caulfield (2000, p. 216) por qualquer que fosse a razão, a maioria dos supostos "defloradores", ao depor diante das autoridades policiais e judiciais, encarnava o papel de moralistas machistas, sustentando normas de gênero desiguais, um padrão duplo de disciplina sexual e um conceito de "posse" sexual em relação às mulheres. Os homens defendiam-se insistindo em que a honra feminina dependia da submissão das mulheres à vigilância patriarcal [...]”' (CAULFIELD, 2000, p. 216).

Melita, de acordo com os autos do processo, era uma jovem que não costumava sair sozinha e quando saía era somente para trabalhar. Namorava José Nunes há seis meses. Nos autos, segundo o depoimento da suposta vítima, o defloramento ocorreu mediante a insistência e a promessa de casamento por parte do deflorador. No entanto, também nos autos constavam elementos que indicavam a deflorada como uma jovem fácil, de conduta duvidosa, dada a libertinagens.

Tais qualificações podem ser identificadas especialmente nos depoimentos de defesa do réu que ao testemunharam a seu favor apontavam a inocência de José Nunes em relação ao defloramento de Melita. Independente das questões e posturas indicadas, o nome da jovem era mais um na lista de mulheres que se viam em meio às discussões sobre a honra feminina e a necessidade de controle do corpo e a preservação da virgindade até o casamento. A proteção do hímen "significava um controle biológico da sexualidade" (MILENGROSSO, 2011, p. 204).

O processo-crime envolvendo o defloramento, apesar de ser considerado sigiloso, ultrapassava as fronteiras do espaço judicial privado, pois havia a participação de inúmeros indivíduos como a vítima, o réu, as respectivas famílias, os vizinhos, os colegas de trabalho, entre outros, os quais se envolviam na discussão sobre a honra dessa vítima e, em alguns casos tais depoimentos podiam por em dúvida a castidade/seriedade/honra dessa mulher. A mulher tinha muitas vezes a sua vida devassada nos autos do processo o que levaria ao 
entendimento se o engano, a sedução haviam realmente ocorrido ou se a conduta da mulher apresenta elementos que comprovariam o seu discernimento sobre o fato ocorrido (defloramento).

Neste sentido, a retórica contida nos processos discutia a honra, a conduta moral, não somente da deflorada, mas também os valores e princípios nos quais a mesma foi educada, colocando em xeque muitas vezes a organização familiar e o papel de responsabilidade da mãe em educar a filha dentro dos princípios de uma conduta de mulher séria.

De acordo com Esteves (1989, p.132)

A vizinhança ou a parentela exerciam influência na vida das pessoas e impunham certos tipos de comportamento. Ou ainda, um momento de conflito por crime por defloramento era a ocasião de mostrar aos demais grandes qualidades morais. Nesse instante, os juízos de valor e preconceitos poderiam ser propalados. Quando um conflito sexual era deflagrado, todos os referenciais sociais e morais eram acionados, iniciando-se uma espécie de disputa política. Passado o conflito todos voltavam a viver normalmente, absorvendo as mudanças e as novidades morais.

Os conflitos travados no âmbito judicial e que são apresentados nos processos criminais vinculados aos crimes de defloramento, trazem à luz as relações de gênero e os papéis determinados para homens e mulheres na sociedade. É importante ressaltar a constante preocupação inerente ao trabalho com qualquer fonte histórica e que não difere no caso de utilização dos processos-crime que muitas vezes reduzem e empobrecem a realidade. Neste sentido, cabe ressaltar a percepção de Chalhoub (2001), ao mencionar a necessidade de buscar nos processos-crime as contradições, as relações estabelecidas, os conflitos presentes nas entrelinhas do texto.

O defloramento considerado um crime sexual envolvia relações de poder como a de gênero, por exemplo, bem como o envolvimento de diferentes interesses e preocupações (punição ou não do culpado, o resguardo da honra das defloradas, com o arranjo de um casamento ou com a punição do denunciado), além disso, envolvia médicos, juristas, advogados, entre outros.

Segundo Caulfield (2000, p.205),

A forma como as jovens das décadas de 1920 e 1930 interpretavam suas relações com o namorado e com a própria família refletia as novas imagens do comportamento feminino. No entanto, as características gerais dos registros de defloramento haviam permanecido as mesmas durante a vigência do primeiro código penal republicano. Moças da classe trabalhadora, ou mais frequentemente seus pais ou responsáveis, recorriam 
à Polícia e à Justiça para que intermediassem os conflitos que envolviam a perda da virgindade, geralmente com a esperança de que as autoridades forçassem os defloradores a se casar.

Não obstante, a virgindade se revestia de um real valor aos pais, pois estava cercada por implicações de ordem prática como a possibilidade de arranjar um bom casamento e constituir família. Para entendermos as questões que cercam a sexualidade feminina, é preciso nos reportamos a mentalidade da época em estudo, que não percebia a sexualidade como "assunto privado", de "emoções individuais", mas como um "patrimônio familiar". $\mathrm{Ou}$ seja, algo que estava vinculado a uma construção social vigente. "Depois de desvirginada, a menina arca quase sozinha com as consequências de sua culpa, antes da perda sua proteção é vista como de responsabilidade de outras pessoas, para justificar a autoridade destas sobre ela" (FONSECA, 1997, p. 530).

Melita aleatoriamente foi eleita por nós como a primeira personagem que instiga nossas reflexões, mas outras tantas jovens passaram pela nossa investigação em busca de respostas para nossas questões, como Maria Normélia Natus, 19 anos, operária, moradora do bairro África ${ }^{4}$, que no ano de 1939 afirmava mediante o juiz que Inocêncio Moren era o responsável pelo seu defloramento; ou como Jenita de Almeida que com 15 anos de idade fora deflorada por Julio Joaquim Ferreira; ou de Maria Noêmia Pereira dos Santos, de cor branca, de profissão serviçal com 19 anos de idade que no ano de 1935 fora deflorada por João Ramos; Julieta Pereira de Oliveira, solteira, operária de cor branca, 20 anos de idade, que fora deflorada no ano de 1938; Maria Albertina de Mello, de 19 anos, de cor branca, solteira, operária deflorada no ano de 1936; Augusta Leal, com 15 anos de idade, cor branca, doméstica deflorada em 1937; em 1939 Cibila Antonia Cardoso, de 15 anos de idade, de cor preta, profissão doméstica, fora deflorada por Carlos Sebastião. ${ }^{5}$

$\mathrm{Na}$ pequena amostra para realização deste estudo, todos os processos foram lidos e analisados e a partir dos mesmos observamos que todas as supostas vítimas eram de condição humilde, trabalhadoras e moradoras das áreas periféricas da cidade de Novo Hamburgo, portanto estamos falando de mulheres pobres. É recorrente nos depoimentos das vítimas que o defloramento deu-se sempre mediante a promessa do enlace matrimonial. Também era comum nos processos analisados o escrutínio sobre a vida da vítima e de sua família, ao contrário do acusado que tinha sua intimidade "vasculhada" moderadamente. No escopo deste estudo, além de Melita dos Santos, nossas reflexões se limitam ao caso de Almerinda Canabarro e de Maria Normélia. Na pesquisa nos deparamos com as mulheres pobres, mas é provável que as mais abastadas também enfrentassem os problemas ligados ao

\footnotetext{
${ }^{4} \mathrm{O}$ bairro África compunha a cartografia periférica do locus em estudo onde habitavam os moradores negros. Também se caracterizava pelo acolhimento de moradores brancos pobres. Atualmente o África é conhecido como o bairro Guarani.

${ }^{5}$ Processos criminais localizados no acervo do Arquivo Público do Estado do Rio Grande do Sul.
} 
controle da sexualidade e os conflitos que cercavam a perda da virgindade, entretanto é possível que outros mecanismos fossem acionados para resolver os desvios cometidos.

Para Saldanha (2001, p. 125), “o que é comum nos processos é a afirmação da testemunha masculina, e às vezes até feminina, de que a moça deflorada certamente teria 'provocado o sedutor'. Nesse caso, a mulher é sempre culpada por aquilo que lhe acontecesse. Mas na fala das vítimas é a promessa de casamento que leva à aquiescência. Elas só permitiram o defloramento porque confiaram na palavra do companheiro, que após ter recebido a "prova", casar-se-ia com elas." A promessa de casamento, os apelos e pressões masculinas mexiam com os sonhos e desejos das jovens, a promessa do enlace matrimonial assegurava momentaneamente as moças que sua condição de mulher séria perduraria, mesmo após a perda da virgindade. Neste sentido, ao que tudo indica, não era somente um desejo de casar-se formalmente, mas também uma busca pelo "direito ao casamento em troca da virgindade" (CAULFIELD, 2000, p. 221).

No entanto, na maioria dos processos crimes analisado para a elaboração deste estudo, o deflorador nega a promessa de casamento mediante as autoridades, bem como busca meios de expor a jovem acusando-a de leviana, faceira, dada a trocar de homens. Os homens tentavam fugir das sanções estabelecidas em lei caso houvesse a comprovação do crime, como, por exemplo, assumir a culpa e casar-se com a deflorada.

$\mathrm{Na}$ retórica dos advogados de defesa do acusado observa-se o apelo para as representações negativas acerca da vítima, muitas vezes usando como contraponto com a positiva constituída socialmente da mulher honrada, aquela que nunca cedia aos apelos sexuais antes de contrair matrimônio. "A mulher honesta era aquela que não sucumbia às tentações que poderiam fazê-la cair do estado de graça" (REICHERT, 2008, p. 26).

Neste sentido, uma disciplina do corpo era exigida, a sexualidade tinha que ser controlada, pois a mulher honrada não se fragilizava diante das tentações corpóreas e sexuais. Uma mulher contida, disciplinada, presa a valorização e defesa da inviolabilidade de uma membrana física (hímen) servia de baluarte para o discurso moral apregoado na sociedade e impunha determinados papéis e espaços permitidos à mulher, construindo uma representação acionada cotidianamente na sociedade.

\section{"Danos inestimáveis..."}

"Infeliz moça, quase menina, recém-entrada na puberdade" é frase que antecede a anotação de mandato de prisão contra Elpídio Klein, o deflorador que segundo os autos apresentou testemunhas que "depuseram falsamente para defender o réu, de quem são 
amigos [...]”. É possível imaginar que Klein, aos 18 anos de idade, um jovem que servia ao exército brasileiro no batalhão de São Leopoldo, não teria avaliado as penalidades e sanções que a ele caberia se ficasse provada a sua responsabilidade em relação à Almerinda Canabarro e a perda de sua virgindade.

No ano de 1936 a promotoria pública apontou que os danos causados a Almerinda Canabarro foram inestimáveis. A queixa encaminhada pela mãe da jovem, Hermina Canabarro levou ao conhecimento da justiça a situação de defloramento da filha de 15 anos através do termo de queixa. No auto de declaração que consta no processo, a vítima foi questionada sobre sua relação com Elpídio, buscando saber da inquirida se ele foi o único a ter cópula carnal com ela. A resposta de Almerinda foi contundente: sim, o único. A promotoria também perguntou se houve a promessa de casamento, e novamente a deflorada respondeu positivamente.

De acordo com as informações contidas no processo crime, os pais de Almerinda eram "miseráveis", e ela, por sua vez, uma moça "séria, honesta, de família, pobre, trabalhadora". Conforme uma das testemunhas inquiridas pelo promotor público, a vítima e a sua família eram honestos e respeitados. "Enquanto vizinhos, sempre mantiveram boa conduta e foram respeitados". A mesma testemunha relata ao promotor que havia visto Elpídio e Almerinda passeando na companhia da mãe da moça.

A perda da virgindade para a mulher solteira a expunha publicamente. A honestidade, nas palavras, de Caulfield (2000, p. 78), era "uma condição social e um atributo moral selados por um estado fisiológico".

A desonra da mulher estava atrelada à condição social e moral, bem como à honestidade, elementos fundamentais os quais eram representados pela conservação do hímen intacto até o enlace matrimonial da jovem. Contudo, a ruptura deste "selo" antes do casamento era, de longe, o ato mais pernicioso que poderia acontecer. Assim a pureza, a castidade, o comportamento recatado era o que se esperava de uma mulher séria e de família, sinônimo de mulher honesta (CAUFIELD, 2000).

Nem todos os processos crimes de defloramento terminavam com o parecer favorável à vítima. Nem todas as jovens arroladas como vítimas contaram com a sentença declarada pelo juiz que julgou o caso de Almerinda. No entanto, cabe destacar alguns aspectos que contribuíram para a condenação de Elpídio e a comprovação da honestidade de Almerinda. Como, por exemplo, a tentativa de Elpídio de provar a sua inocência em relação ao defloramento, bem como a tentativa de provar a vida leviana da vítima através de falso testemunho.

As testemunhas de Elpídio, as quais se comprometeram em falar a verdade em juízo, narraram episódios em relação à Almerinda. Como o fato de um dos depoentes de Elpídio 
ter mantido cópula carnal com a jovem, estabelecia-se a caracterização de uma mulher de conduta duvidosa e leviana. No entanto, na avaliação do juiz, amparado em informações coletadas in loco (inquerindo testemunhas, através de depoimentos de vizinhos, colegas de trabalho) não procedia o mencionado pelo depoente. Além disso, conforme a autoridade, os depoimentos em defesa do réu não mereciam consideração, pois não eram idôneos por se tratarem de amigos íntimos do acusado.

Por sua vez, os depoimentos de defesa da honestidade de Almerinda foram considerados idôneos. Esses trouxeram à tona valores norteadores da sociedade não só em âmbito nacional como também local, tais como: família, trabalho, honra e ordem. A família de Almerinda foi indicada como uma família pobre, mas de trabalhadores. Os indivíduos pertencentes à família eram avaliados como bons vizinhos, o que poderíamos interpretar como sendo uma indicação de não envolvimento em conflitos com a vizinhança; uma família tranquila, ordeira, obediente e norteada pelos bons costumes, ou seja, uma conduta coerente com uma moral apregoada na época.

A valorização do trabalho e da família estava presente nas premissas sociais desde o início da República no Brasil, o ideal para uma sociedade civilizada era um trabalhador ligado ao lar, espaço da virtude e da família, local onde estava protegido dos vícios, bebedeiras e jogos. Os testemunhos atestando a família de Almerinda como honesta, trabalhadora e virtuosa certamente acrescentaram informações importantes que pesaram na decisão do juiz. Acionava-se, assim, conceitos disseminados e valorizados não somente no espaço jurídico (tribunal), mas também fora dele. Outro elemento que merece destaque a partir do processo criminal que coloca Klein como réu é a tentativa do acusado de mostrar a deflorada como não sendo "de família", pois andava copulando nos "matinhos".

A esfera pública e privada era acionada para tentar denegrir a imagem de Almerinda. As ruas, os bailes, as festas somente eram permitidos às moças sérias quando acompanhadas de um familiar. Uma "moça donzela" somente frequentaria um baile acompanhada da mãe, ou de outra mulher mais velha, comprovadamente séria e de conduta ilibada. Somente as mulheres fáceis e sem moral circulavam desacompanhadas. Mulheres honestas não entravam em "matinhos" ou andavam em estradas pouco movimentadas. Acionava-se não só uma disciplina do corpo imposta à mulher, como também uma disciplina de movimentação e de deslocamentos permitida ao corpo feminino. Andar por alguns espaços públicos implicava em um estigma, as ruas eram para as mulheres descomprometidas com a honestidade, de conduta duvidosa, de vida irregular, portanto, sujeitas as investidas masculinas justificáveis socialmente. A rua era para os desviantes.

Esteves (1989) considera que os crimes sexuais contavam com duas tendências por parte da Justiça: uma era que excluía as moças pobres da proteção jurídica, caso comprovasse que as mesmas eram desordeiras e de vida fácil; a outra tendência 
caracterizava-se pela intervenção nos crimes de defloramento com prisões e condenações do réu, uma tentativa de estabelecer a ordem moral.

Para a autora as tendências são divergentes e complementares, já que de uma forma ou de outra o papel jurídico reforçava condutas desejadas e reprimia as indesejadas (ESTEVES, 1989, p. 83). No caso de Elpídio, o juiz decretou a sentença que atestava a figura de transgressor (de normas e condutas morais e sociais) assumida pelo acusado ao deflorar Almerinda e de tentar enganar as autoridades.

\section{"Serviço mal feito"}

Os processos investigados envolvem trabalhadoras, pessoas humildes e moradoras dos arrabaldes da cidade que prosperava e crescia a partir da industrialização. O bairro África é um espaço recorrente nos autos dos processos investigados e era nessa localidade que morava Maria Normelia Natus, operária, solteira, 19 anos de idade. O caso de Maria Normélia, não difere dos demais processos analisados, chega até as autoridades policiais através da denúncia do responsável que poderia ser o pai, a mãe, ou um parente mais próximo.

Neste caso, a denúncia sobre o defloramento de Normélia partiu da mãe, Hilda Natus, 43 anos, viúva. Na delegacia a mãe declarou ao delegado Alfredo Cidade que Inocencio Moren, há mais de um ano era "namorado da sua filha" e que há "mais ou menos vinte e seis dias" o acusado e a filha ficavam conversando de noite na sala de sua casa, enquanto que a depoente ia deitar-se encostando a porta que comunicava a sala com o quarto. Segundo Hilda, foi em uma dessas ocasiões que o acusado deflorou a sua filha.

Maria Normélia, em sua declaração, identificou-se como namorada do acusado "há mais de ano", no entanto, segundo ela, há seis meses mais ou menos, mediante as propostas indecorosas do namorado ela o tinha repelido, o que haveria estremecido a relação com o rapaz, mas, passado algum tempo, reconciliaram-se.

Segundo a declaração da jovem operária, "aos vinte e seis do mês de outubro, pelas dez e meia horas da noite, ela e seu namorado achavam-se na sala de sua casa quando este quis manter relações sexuais, dizendo que, caso ficasse certificado de que ela era virgem, ele repararia o mal pelo casamento". Ainda é acrescentado pela ofendida em sua declaração que "depois de mantidas as relações, o que ocorreu na sala referida junto a porta da cozinha, o acusado disse que não contasse nada a sua mãe, pois no dia seguinte voltaria ali para tratar a data do casamento." 
No rol de testemunhas, dois rapazes, ambos operários e maiores de idade, atestaram que nunca ouviram nada sobre Maria Normélia que a desabonasse. Uma das testemunhas afirmava que Inocêncio "há mais de ano namorou a ofendida; que até agora o acusado costumava ir quase todos os sábados na casa da ofendida" e quando esta arrumava algum namorado, Inocêncio tratava logo de incentivar sua atenção para com a ofendida a fim de afastar o rival.

Já Inocêncio, analfabeto, sapateiro, também morador do bairro África, por sua vez declarou que Maria Normélia foi sua namorada por algum tempo, mas que não tinha mais nenhuma relação com a moça, porém acompanhava a jovem e sua mãe muitas vezes para que elas não andassem sozinhas nas ruas desertas e escuras, já que mãe e filha frequentavam a sua casa. Segundo o sapateiro, ao deixá-las em casa, Maria Normélia teria se oferecido para voltar com ele para casa, no entanto como ignorava se a moça era virgem não aceitou a proposta.

No depoimento do rapaz ainda consta que "certificou-se com os dedos que a ofendida não era mais virgem". Inocêncio informa em sua declaração que ao tentar sair da residência foi impedido, pois Normélia "segurou-lhe pelo casaco arrastando-o para perto de um fogão onde tiveram relações sexuais". Após o ato, a ofendida reclamou porque "o serviço não havia sido bem feito". O acusado afirma no seu depoimento "não ter prometido casamento nem antes e tampouco depois da cópula carnal."

O rol de testemunhas no processo de defloramento de Maria Normélia não é muito extenso se comparado ao processo de Melita e Almerinda. Diferente do caso de Almerinda, a promotoria pública concluiu a não existência de crime de defloramento para Maria Normélia. No processo é indicado que o que "houve não foi mais do que a comum vontade de ambas as partes." Tal entendimento por parte do promotor estava respaldado especialmente no exame de corpo-delito onde constava: "Hímen com pequeno pertuito central, regularmente inserido e sem fissura alguma" e a negativa para a existência de defloramento ou estupro.

Além disso, na leitura das autoridades responsáveis pelo caso e amparando-se nas investigações realizadas foram indicados dois aspectos que não permitiram a caracterização de crime de defloramento. Primeiro: "a ofendida, de físico reforçado, bem podia ter dado alarme, o que isso não aconteceu, pois em caso afirmativo, a sua mãe, que se encontrava a uma peça junta, onde existia uma porta de comunicação que estava apenas encostada, teria notado qualquer movimento anormal." Segundo: "a mesma razão persiste em contradição com a afirmação do acusado que, conforme suas declarações, assume o papel de vítima, dizendo que só praticou o ato depois de diversas tentativas de fuga frustradas." 
Não sabemos se Maria Nomélia realmente reclamou do "serviço mal feito" de Inocêncio, ou se a reclamação registrada no depoimento do acusado pode ser entendida como uma estratégia por parte do rapaz de se livrar das acusações ou do casamento forçado. Ou ainda, que ao apontar a cobrança de Maria Normélia acabava indicando que a mesma não era ingênua e inocente, pois sua atitude de dizer que o serviço não fora bem feito não era algo permitido as mulheres, ou seja, uma avaliação, uma exigência em relação a sexualidade.

Nossas indagações "sobre o serviço mal feito" configuram somente um exercício de pensar acerca das (in) possibilidades históricas. ${ }^{6}$ A reclamação da jovem talvez tenha relação com as sensibilidades, desejos e vontades presentes na sexualidade feminina e que eram reprimidos, negados por uma moralidade e não permitidos para as mulheres de família. O serviço mal feito poderia ter relação com a exposição desta mulher que soube no dia posterior ao "suposto defloramento" que Inocêncio gabava-se para outros rapazes do bairro que havia deflorado Normélia. Talvez ela também tenha lançado mão da dúvida sobre a competência sexual de Inocêncio como uma estratégia de desmoralizar o rapaz, uma vingança por tornar público um ato que deveria ficar restrito ao espaço privado.

A intimidade de Normélia havia sido denunciada, mas a incompetência do acusado também, assim, a jovem mexia com os brios masculinos tornando público o ato falho de Inocêncio. A jovem lançava mão do "valor de uso da hegemonia", em outras palavras, "a capacidade dos subordinados de conduzirem seus interesses dentro do discurso oficial de deferência e contra as autoridades instituídas" (MILENGROSSO, 2011, p. 210). O hímen não rompido certamente não ajudaria Maria Normélia a distanciar-se do estigma da mulher "tocada" por um homem o que dentro da moralidade da época já revertia em um grande fardo social.

No caso de Maria Normélia, não se percebe uma discussão mais ampla sobre a honra da suposta vítima e de sua família. Talvez, como referido anteriormente, o fato do exame de defloramento e de estupro ter dado negativo o caso estava resolvido sem a necessidade de envolver um rol maior de testemunhas e sem prolongar e onerar os cofres públicos com um processo crime que não ocorreu.

Por outro lado, o fato da jovem ter dezenove anos de idade e sua mãe mencionar que deixava a porta encostada do seu quarto que era "colado" a outra parte da casa (cozinha),

\footnotetext{
${ }^{6}$ Ao pensarmos sobre possibilidades históricas nos respaldamos no entendimento de Henrique Espada Lima (2006) que ao discutir a micro- história italiana e apresentar algumas reflexões sobre a obra do historiador italiano Carlo Ginzburg menciona a importância no jogo interpretativo que articula dados seguro e conjecturas. Expressões como "talvez", "muito provavelmente", "possivelmente", não sinalizam "uma análise titubeante ou pouco rigorosa, mas ao contrário. O uso de uma "linguagem de probabilidade", tenta enfatizar a natureza colocada no jogo de análise (LIMA, 2006, p.358-369).
} 
colocava ambas, mãe e filha, em condições de zelar pela virgindade da jovem. A jovem e sua mãe poderiam ter controle sobre o corpo que deveria ser fiscalizado, disciplinado, obediente à conduta de mulher séria.

Se trabalharmos a perspectiva de que os processos crimes que tinham o defloramento como foco tornavam-se públicos, especialmente por envolverem outros sujeitos (vizinhos, parentes, entre outros), poderíamos inferir que nesse processo envolvendo Inocêncio e Maria Normélia, ela teria recebido as marcas da desmoralização, pois, certamente, seu nome fora associado ao termo deflorada e marcado por um ônus moral. É muito provável que, pelo menos por algum tempo, seu nome fora foco das fofocas da vizinhança e de parentes, situação essa que em uma cidade pequena facilmente estigmatizava um indivíduo.

Mas, por outro lado, para uma sociedade que também cobrava uma postura de virilidade masculina, um "serviço mal feito" propagado publicamente poderia, no mínimo por algum tempo, deixar algumas marcas. Nesse caso, talvez não tão profundas se comparadas com as que convergiam para as mulheres, mas, no mínimo entres seus pares, o cotidiano de Inocêncio seria afetado com comentários maldosos, fofocas, deboches. Neste sentido, tornando o "serviço mal feito" público, Maria Normélia sentiu-se um pouco mais reconfortada com os danos que o episódio provavelmente causou a ela e a sua mãe. No final, de acordo com as autoridades "Inocêncio era inocente" e poderia seguir com sua vida. Quanto a Maria Normélia, nada consta nos autos sobre a sua vida a partir do processo de defloramento.

\section{Considerações Finais}

A história instiga a imaginação e nos leva a pensar nos personagens como atores sociais carregados de humanidade, portanto, sensíveis, ardilosos, sonhadores, ou seja, personagens com vida própria. Ao falarmos de mulheres e seus corpos neste artigo, nos remetemos especificamente às mulheres da década de 1930, moradoras da pacata e tranquila cidade de Novo Hamburgo, situada no Vale do Rio dos Sinos (RS). Trabalhamos especificamente a partir dos processos crimes de três personagens: Melita dos Santos, Almerinda Canabarro e Maria Normélia Notus, escolhidas aleatoriamente.

Não diferente de outros espaços do imenso Brasil, no imaginário da cidade onde a industrialização apoiada no setor coureiro-calçadista progredia, existiam as mulheres indicadas como fáceis, de conduta duvidosa e as mulheres sérias, de famílias, mulheres para casar. Nos meandros de uma tessitura social complexa, muitas mulheres travaram uma luta 
contra as marcas estabelecidas a elas quando buscavam na delegacia e em juízo a defesa da sua honra.

Neste artigo, perquirimos abordar as representações construídas sobre a mulher, bem como as relações de gênero presentes no processo criminal de defloramento. Nosso objetivo foi relacionar a valorização constituída socialmente sobre o hímen feminino e o controle sobre o corpo da mulher como forma de demarcar espaços e (im) possibilidades sociais.

Os estudos citados ao longo do trabalho abordam que os ideais burgueses apesar de serem propagados como referenciais, os quais objetivam atingir e disciplinar o conjunto da sociedade, nem sempre eram atingidos, posto que os ideais burgueses antagonizavam com ideais, desejos, realidade e necessidades das camadas mais pobres que lutavam cotidianamente pela sobrevivência e que tinham leituras distintas sobre valores, regras e normas.

Como destacamos, trabalhamos com as mulheres pobres, que viviam em situações menos privilegiadas e lutavam cotidianamente por um espaço na sociedade através do trabalho, da necessidade de sustentar a prole e de lutar por uma honra que foi muitas vezes negociada no momento que antecede o ato de "desvirginamento". Mulheres que circulavam pelo mundo do trabalho como operárias, serviçais, domésticas, na maioria jovens, que muitas vezes ao sair a rua para trabalhar eram vistas como libertinas, mas que ao mesmo tempo necessitavam contribuir com o sustento da família ou mesmo sustentá-la sozinha.

Melita Santos, Almerinda Canabarro e Maria Normélia pertenciam a um mesmo cenário histórico, mas seus processos e suas vidas tinham particularidades e singularidades. Talvez em outro momento a releitura de cada processo indicado nos leve a conhecer mais e melhor a diversidade que cercava esse "mundo das mulheres".

É provável que muitos indícios não tenham sido por nós percebidos ou pensados de forma satisfatória, mas não vemos isso como um demérito, pois acreditamos que pensar sobre os anonimatos e os silêncios inspira a necessidade de continuarmos nos aproximando dos distintos personagens como forma de pensar a multiplicidade dos atores sociais que construíam a história de Novo Hamburgo, além de tentarmos compreender de forma mais ampla discursos e práticas que envolviam as mulheres e os homens em uma cidade pacata e "ordeira", mas cheia de tensões e conflitos.

REFERÊNCIAS BIBLIOGRÁFICAS

AMANTINO, Márcia; DEL PRIORE, Mary. História do corpo no Brasil. São Paulo: UNESP, 2011. 
BRUSCHINI, Cristina. Mulher, casa e família. São Paulo: Fundação Carlos Chagas/Vértice, 1990.

CASTILHO, Kathia. Moda e linguagem. 2. ed. São Paulo: Anhembi Morumbi, 2009. Coleção Moda e Comunicação.

CAULFIELD, Sueann. Em defesa da honra. Moralidade, Modernidade e Nação no Rio de Janeiro (1918-1940). São Paulo: UNICAMP, 2000.

CHALHOUB, Sidney. Trabalho, Lar e Botequim. Campinas: Ed. UNICAMP, 2001.

CHARTIER, Roger. A história cultural. Lisboa, Bertrand/Difel, 1990.

ESTEVES, Martha de Abreu. Meninas Perdidas. Os populares e o cotidiano do amor no Rio de Janeiro da Belle Époque. Rio de Janeiro: Paz e Terra, 1989.

FAUSTO, Boris. Crime e cotidiano. São Paulo: EDUSP, 2001.

FONSECA, Cláudia. Ser mulher, mãe e pobre. In: PRIORE, Del Mary. História das Mulheres no Brasil. São Paulo: Contexto, 1997. p. 510-553.

GARCIA, Wilton. Corpo, Mídia e Representação: estudos contemporâneos. São Paulo: Pioneira Thomson Learning, 2005.

LIMA, Henrique Espada. A micro-história italiana. Escalas, indício e singularidades. Rio de Janeiro: Civilização Brasileira, 2006.

MAGALHÃES, Magna L. Entre a preteza e a brancura brilha o cruzeiro do sul: Associativismo e identidade negra em uma localidade teuto-brasileira (Novo Hamburgo). Tese de Doutorado PPG-UNISINOS, São Leopoldo, 2010.

MILENGROSSO, Carlos Eduardo. Honra e conduta: Populares e práticas amorosas em Porto Alegre (18981923). Revista Crítica Histórica, ano II, n.4. dez, 2011.

MORAES, Andrea. O corpo no tempo: velhos e envelhecimento. In: AMANTINO, Marcia: DEL PRIORE, Mary. História do corpo no Brasil. São Paulo: UNESP, 2011. p. 427-452.

PETERSEN, Sílvia. A mulher na imprensa operária gaúcha do século XIX. Revista História, v.1, 1986/87.

PRIORE, Mary Del. História íntimas. Sexualidade e erotismo na história do Brasil. São Paulo: Planeta, 2011.

RAGO, Margareth. Do cabaré ao lar: A utopia da cidade disciplinar - Brasil 1890-1930. 2. ed. Rio de Janeiro: Paz e Terra, 1987.

REICHERT, Emannuel Henrich. A sedução e a honestidade: representações de genero nos processos de crimes sexuais (Porto Alegre, 1920-1926). Porto Alegre: UFRGS, 2008. Monografia de conclusão.

SALDANHA, Terezinha. Amor Proibido ou crime de sedução. Violência e poder nas representações jurídicas nos processos crimes (1900-1930). Analecta, Paraná. v.2, n.3, jul/dez. 2001, p.121-140.

SCOTT, Joan. Gênero: uma categoria útil para análise. Disponível em http://disciplinas.stoa.usp.br/pluginfile.php/6393/mod resource/content/1/G\%C3\%AAneroJoan\%20Scott.pdf. Acesso em 27/06/2015. 
SELBACH, Jeferson. Novo Hamburgo 1927-1997: Os espaços de sociabilidade na gangorra da modernidade. Dissertação (Mestrado), Universidade Federal do Rio Grande do Sul, 1999.

SOARES, Carmen. Corpo, conhecimento e educação. In: SOARES, Carmen (org). Corpo e História. 2 ed. Campinas, SP: Autores Associados, 2004.

SOIHET, Rachel. Mulheres pobres e violência no Brasil urbano. In: PRIORE, Del Mary. História das mulheres no Brasil. São Paulo: Contexto, 1997. p.362-400.

SCHWARTZMAN, Simon et alii. Tempos de Capanema. São Paulo: Paz e Terra/EDUSP, 1984.

SOARES, Carmen. Corpo, conhecimento e educação. In: SOARES, Carmen (org). Corpo e História. 2 ed. Campinas, SP: Autores Associados, 2004.

SILVA, Ana Márcia. Corpo, ciência e mercado: reflexões acerca da gestação de um novo arquétipo de felicidade. São Paulo: Autores Associados: Florianópolis: Editora da UFSC, 2001. 